Research Article

\title{
Training Needs in Light of the Degree of Awareness of Modern Teaching Strategies and Their Application in the Tertiary Level during the COVID-19 Pandemic
}

\author{
AbdulAziz R. Alamro \\ Curriculum and Instruction, University of Hail, Ha'il, Saudi Arabia \\ Correspondence should be addressed to AbdulAziz R. Alamro; dr.alamr@uoh.edu.sa
}

Received 19 May 2021; Revised 13 July 2021; Accepted 6 October 2021; Published 3 December 2021

Academic Editor: Ehsan Namaziandost

Copyright (C) 2021 AbdulAziz R. Alamro. This is an open access article distributed under the Creative Commons Attribution License, which permits unrestricted use, distribution, and reproduction in any medium, provided the original work is properly cited.

\begin{abstract}
This study aimed to evaluate modern teaching methods applied by the staff at the University of Hail during the COVID-19 pandemic to identify the most important causes, needs, and barriers from their perspective. Also, the study aimed to reveal individual differences (gender, academic rank, or experience) of statistical significance in the staff's degree of use. To achieve the objectives of the study, the researcher used descriptive analysis on a sample of 164 faculty members. The researcher designed a fiveaxis questionnaire. The results indicated the importance of e-training when using modern teaching methods. Also, it was clear that the research sample uses MTM to some extent, and the use of modern teaching strategies was found to be moderate. Gender, academic rank, years of experience in the field of university education, and academic specialization did not affect training needs. In addition, the results showed that the most important reason for using MTM during the COVID-19 pandemic was "Mastery of how to use it."
\end{abstract}

\section{Introduction}

University teaching is a vital function that effectively prepares students for the future, arming them with specialized knowledge, positive behavioral trends and values, and necessary scientific and practical skills to render them as active community members [1]. A faculty member's role is beyond transferring knowledge, as the primary purpose of teaching is to bring change in the learner to achieve the targeted results [2].

Traditional teaching methods are methods used by most teachers to varying degrees, including the following: (a) teacher lecturing and student note taking, (b) individual student pen-and-paper practice problems, (c) pen-and-paper assessment, (d) laboratory activities with predetermined outcomes in science classes, and (e) discussions [3]. Traditional learning methods (teacher-centered methods) failed to meet the educational process requirements during the pandemic. Modern learning methods require a learner-centric approach to effectively prepare students for the future through active learning. The evolution of the role of teachers and learners has become a necessity to remain contemporary [4].

Theresa [5] stresses that updating curricula means providing new content for the material and novel teaching methods, making the curriculum more effective by creating active situations that allow for positive participation in the learning discovery. This increases the depth of learning experiences with real-life functional skills [6-9].

Studies revealed the causes of students' poor performance were ineffective teaching methods that disregard individual differences and technological innovations [10-12].

Therefore, it is necessary to first identify and utilize modern teaching methods [13]. Secondly, we must identify training needs, obstacles, challenges, and priorities to uncover gaps. Decision makers should provide solutions to enhance training programs $[2,14-16]$. 
1.1. The Study Problem. Faculty members play a vital role in preparing and qualifying educational outcomes according to contemporary requirements. Currently, two methods of teaching exist: traditional and modern teaching methods [17]. One of the greatest challenges in lectures is the ability to meet all learning styles and the diverse needs of students.

Studies revealed that the educational practices of university staff were not optimal $[15,18]$.

Also, it was found that the most impactful impediment to using modern teaching methods is teachers' lack of awareness on the importance of keeping up with recent developments and training [1, 19].

In-service training programs and the employment of modern teaching methods are of immense importance. It is vital to train teachers on the use of active learning strategies and emulate some other university experiences during the COVID-19 pandemic [20, 21].

The researcher also interviewed a group of faculty members, discussing modern teaching methods. The interviews concluded that there is a lack of understanding and training in modern teaching methods for use in proper ways.

The research problem is "the weak use of modern teaching methods at the UOH during the COVID-19 pandemic due to obstacles and training requirements among university staff according to their awareness of modern teaching strategies and their application in teaching."

\subsection{Questions}

(1) How extensively does UOH staff use MTM?

(2) Why is MTM used by UOH staff from their point of view?

(3) What are the obstacles hindering the use of MTM from $\mathrm{UOH}$ staff's view?

(4) What are training needs do $\mathrm{UOH}$ staff need for MTM from their point of view?

(5) What are the proposed training methods to develop the skills of MTM using UOH staff from their point of view?

(6) Are there statistically significant differences, at the level of 0.05 , in the responses of the study sample in the degree of staff's use of MTM attributable to a specific variable (gender, academic rank, years of experience, or academic specialization)?

1.3. Goals. The study seeks to assess MTM usage by the $\mathrm{UOH}$ staff and identify the most important reasons for using/not using MTM from their point of view. Also, the study aims to identify the most important training needs for using MTM and determine the best training methods to develop their skills.

This may be useful in assessing the current usage of MTM, allowing the development plans to improve their performance based on actual training needs. Moreover, these facilitators responding to modern trends call for an increased interest in MTM.
1.4. Theoretical Framework. The novel coronavirus disease (COVID-19) outbreak transformed daily life. The disease hindered education, as instructors must deliver lectures safely while ensuring the integrity and continuity of the education process. The highly contagious nature of the virus has made it challenging to continue lectures, prompting teachers to use MTM.

MTM development and application for the educational process allows students to self-learn, collaborate, and participate. Therefore, professional development in education to expand the use of MTM requires effective training programs to achieve tangible needs-based development. Colleges and universities rely heavily on qualified staff [22], especially during the COVID-19 pandemic.

1.4.1. Modern Teaching Methods. Teaching methods are the various strategies that a teacher uses to present knowledge to students according to educational objectives to achieve the learning outcomes. They help teachers to teach and communicate ideas and skills to students. Numerous and diverse teaching methods exist. This diversity leads to diverse philosophical and educational theories on which they are based, and the varying educational positions require a suitable method [5]. Beichner [23] defines the most important specifications of MTM as follows: (1) comprehensiveness, (2) flexibility, adaptability, and development, (3) objective-based teaching, (4) addressing individual differences, and (5) accounting for the type of teaching (individual/group).

1.4.2. Active Learning-Based Teaching Methods. Active learning-based teaching methods are educational activities directing students to act and contemplate their actions. Hartikainen et al. [24] define them as the presence of ideas in the cognitive structure of the learner linked to the presented ideas, where the learner perceives them. The cognitive conflicts faced through participation, dialogue, and classroom interaction in organized groups and educational activities guide toward higher levels of thinking. The represented procedures and methods are considered the executive and procedural aspects of active learning, contributing to achieving the desired educational goals efficiently.

Many teaching strategies suit active learning. Professors must realize that there is no perfect strategy or method; appropriate strategies vary with lessons or situations and students. Teaching methods have changed due to social changes requiring university education to adapt to a complex reality. The first step is to define the characteristics of modern teaching methods, shifting the paradigm from the teacher as a provider of knowledge to the student as an acquirer of knowledge, where the student is not a passive recipient anymore but an active efficient researcher in the process of building and applying knowledge and skills [25].

Konopka et al. [26] believe that active learning is achievable through actively engaging teaching methods in the process of authentic learning, replacing memorization and repetition. On the other hand, this learning focuses on 
continuous intellectual participation. Active teaching engages students in curricular content, promoting the development of their procedural knowledge and its integration with declarative and metacognitive knowledge.

\subsubsection{Prominent Active Learning-Based Modern Teaching} Methods. By analyzing the most important studies and literature that dealt with modern teaching methods based on active learning $[7,9,20,27-32])$, the following modern teaching methods are believed to be the most important active learning methods: cognitive KWL teaching strategy, concept mapping, brainstorming, problem solving, directed discovery, inductive, inquiry, and project-based learning, reciprocal teaching method, think, peer assessment-teaching method, learning by modeling, mastery learning, roleplaying, peer learning, cognitive load teaching strategy, and think-pair-share.

1.4.4. Teacher Roles in Active Teaching. The teacher's role is to guide and facilitate learning, study, investigation, interstudent dialogue, communication, free flow of ideas, and cooperation. In addition, the teacher should provide an adequate psychological atmosphere inside or outside the classroom, allowing students to cooperate and communicate and acquire knowledge, skills, desired trends, and values [17].

1.4.5. Training Needs. Training needs are the sum of the changes required to be conducted by the teacher regarding information, experiences, performance, behavior, and trends to better situate them for the job. They indicate the difference between individuals' current and desired performance due to their lack of knowledge, capabilities, and skills [6]. The training process is the process of providing employees with the appropriate skills and knowledge to perform a specific job. It is a planned procedure aimed at empowering employees with the information and skills necessary to improve their performance. According to Mohamad and Al-Faqih [33] and Nassar [34], a training strategy correlates with the organization's strategy. The training strategy should be based on threats, opportunities, weaknesses, and strengths in the work environment to meet challenges and utilize available environmental opportunities. Devising training objectives depends on strategic analysis to ensure its integration within the organization's strategy.

Shoaib and Asfour [13] indicated that training while serving as faculty members is one of the most important aspects of developing the teaching process and faculty members' performance. Therefore, some universities make it a necessary condition for practicing the profession. Some university staff training programs tend to make it one of the responsibilities of the university that attract specialists and qualified experts to develop the capabilities of university teachers. The results of a study clarify this more [18], focusing on the necessity of workshops, courses, and training programs covering how to employ modern teaching strategies and methods at the university level.

\section{Methods}

2.1. Research Community and Sample. The study population consisted of all staff at the UOH. A stratified random sample was selected from the research community, consisting of 164 individuals representing the university colleges as shown in Table 1.

2.2. Approach. The researcher used descriptive and analytical approaches due to the nature of the study.

2.3. Limitation. The study was conducted during the academic year 2019/2020 at UOH and its branches. The study included a sample of the staff in health, engineering, and humanitarian colleges.

2.4. Study Tool (e-Questionnaire). The general purpose of the tool was "Determining the reality of the use of MTM by staff at the $\mathrm{UOH}$ and determining training needs from their point of view and the training method that meets their needs." The questionnaire phrases were drafted and presented to experts to review and agree upon. Then, it was uploaded to Google Drive.

The questionnaire was tailored to the study, down to its objectives and questions, data and information required, and perusal of the literature and previous studies. The questionnaire had five main axes: The first axis was $\mathrm{UOH}$ staff's extent of MTM use, including 11 modern strategies accessed through analyzing previous sources and studies and the researcher's experience in the field of university teaching. The second axis was the reasons for MTM use, consisting of 11 reasons. The third axis was the obstacles to MTM use from the staff's point of view, amounting to 11 difficulties. The fourth axis was training needs required for MTM. And the fifth axis was the proposed training methods to develop staff's MTM use.

To ensure the questionnaire's validation, it was distributed to 50 university staff members outside the research sample. The correlation coefficients of the items of the questionnaire with the total score were extracted for each item in the form of a correlation coefficient between each item and the total score, each item and its correlation with the axis to which it belongs, and each axis and the total score. The correlation coefficients of the items with the axis were $0.52-0.88$ and with the tool as a whole were $0.46-0.87$, as in Table 2.

From Table 2, all the correlation coefficients were of acceptable degrees and statistically significant. Therefore, none of these paragraphs was omitted. Regarding correlation coefficients between the dimensions to each other and the tool as a whole, Table 3 details them.

2.5. Stability. The tool's stability was ascertained via testingretesting by distributing it to 50 staff members outside the research sample for two times separated by two weeks. The Pearson correlation coefficient was calculated between the two applications, and the stability (internal consistency) 
TABLE 1: A description of the variables of the study sample.

\begin{tabular}{|c|c|c|c|c|}
\hline No. & Variable & Level & No. & Percentage \\
\hline \multirow{3}{*}{1} & \multirow{3}{*}{ Gender } & Male & 104 & 63.4 \\
\hline & & Female & 60 & 36.6 \\
\hline & & Total & 164 & 100 \\
\hline \multirow{4}{*}{2} & \multirow{4}{*}{ Years of experience } & Less than 10 years & 41 & 25 \\
\hline & & From 10 years to 15 years & 48 & 29.3 \\
\hline & & Over 15 years & 75 & 45.7 \\
\hline & & Total & 164 & 100 \\
\hline \multirow{5}{*}{3} & \multirow{5}{*}{ Academic rank } & Professor & 3 & 1.8 \\
\hline & & Associate professor & 47 & 28.6 \\
\hline & & Assistant professor & 61 & 37.1 \\
\hline & & Lecturer & 53 & 32.3 \\
\hline & & Total & 164 & 100 \\
\hline \multirow{4}{*}{4} & \multirow{4}{*}{ Academic specialization } & Geometry & 41 & 25 \\
\hline & & Healthy & 48 & 29.2 \\
\hline & & Humanitarian & 75 & 45.7 \\
\hline & & Total & 164 & 100 \\
\hline
\end{tabular}

between the paragraphs was calculated using the Cronbach alpha. The overall stability factor was 0.95 , while the overall stability coefficient was 0.94 . These values were acceptable. Table 4 illustrates this.

\section{Results}

To answer the $1^{\text {st }}$ question, averages and standard deviations were calculated for the questionnaire responses on the reality of the use of MTM by the UOH staff in the first axis. Table 5 illustrates these results.

From Table 5, the general average of responses on the first axis was 1.94, indicating that there is an agreement to a degree ("use somewhat") in the first axis: the degree of use. The value of the standard deviation of the general mean of the axis was 0.184 , indicating a significant heterogeneity of responses.

The results indicate that the research sample uses MTM to some extent. This is attributable to their tendency to use nontraditional teaching methods and awareness of the importance and observance of educational principles that contribute to preparing the integrated personality of the learner during the COVID-19 pandemic, besides their observance of individual differences between learners and previous experiences.

To answer the $2^{\text {nd }}$ question, the averages and standard deviations were calculated for the questionnaire responses concerning the use of MTM by the UOH staff in the second axis, as shown in Table 6.

Table 6 shows that the general average on the second axis was 2.20, indicating that there is an agreement on the paragraphs of the axis. The value of the standard deviation of the general mean of the axis was 0.242 , which is an indication of the homogeneity of the sample responses.

To answer the $3^{\text {rd }}$ question, averages and standard deviations were calculated for the questionnaire responses concerning the UOH staff that uses MTM, as in Table 7.

Table 7 shows that the general average of the sample responses on the $3^{\text {rd }}$ axis was 1.55, indicating that there is a consensus (disagreement) with the paragraphs of the questionnaire in the third axis. The value of the standard deviation of the general mean of the axis was 0.225 , indicating the homogeneity of responses.

This could be due to the staff's mastery of modern teaching strategies and their realization of their real role when implementing these strategies consistently when achieving an awareness of the student's role during implementation.

The staff's disagreement with these obstacles could be an indication of their lack of need for these methods from their point of view. For example, the last of these obstacles came in the case of disagreement, "it does not take into account individual differences." They see that MTM has the strength to stimulate students and account for individual differences. They see that their capacity to use MTM is one of the factors that helps in overcoming these obstacles. Also, in second place came "I see that it consumes the time and effort of the university teacher" because it requires effort and preemptive preparation. The third obstacle was the degree of disagreement "I feel that I need training beforehand on how to use them," indicating their awareness of MTM's importance and their need to train on them.

To answer the $4^{\text {th }}$ question, averages and standard deviations were calculated for the questionnaire responses concerning the UOH staff's use of MTM. Table 8 illustrates these results.

Table 8 shows that the general average of the sample responses on the fourth axis was 1.86, indicating the agreement with the degree of need (medium) for the paragraphs of the fourth axis. The standard deviation of the general mean of the axis was 0.196 , indicating the homogeneity of responses.

The averages for the items in Table 9 show an urgent need to identify and train the staff on half of the elements of this axis, lying between high and medium within 1.12-2.46.

This is explained by the fact that the staff believe that they need to know everything related to these methods that focus on self-learning due to their direct impact on the educational process during the COVID-19 pandemic: their motivation, eagerness to stimulate students, and their involvement in the educational situation. 
TABLE 2: The correlation coefficient values between the paragraphs of the tool and the dimension to which it belongs and its overall mark.

\begin{tabular}{|c|c|c|c|c|c|}
\hline $\begin{array}{l}\text { Paragraph } \\
\text { no. }\end{array}$ & $\begin{array}{l}\text { Correlation coefficient } \\
\text { with the axis }\end{array}$ & $\begin{array}{l}\text { Correlation coefficient } \\
\text { with the tool }\end{array}$ & $\begin{array}{c}\text { Paragraph } \\
\text { no. }\end{array}$ & $\begin{array}{l}\text { Correlation coefficient } \\
\text { with the axis }\end{array}$ & $\begin{array}{l}\text { Correlation coefficient } \\
\text { with the tool }\end{array}$ \\
\hline 1 & 0.70 & 0.53 & 29 & 0.83 & 0.74 \\
\hline 2 & 0.76 & 0.65 & 30 & 0.48 & 0.49 \\
\hline 3 & 0.60 & 0.54 & 31 & 0.70 & 0.53 \\
\hline 4 & 0.70 & 0.53 & 32 & 0.71 & 0.87 \\
\hline 5 & 0.66 & 0.46 & 33 & 0.82 & 0.55 \\
\hline 6 & 0.59 & 0.73 & 34 & 0.82 & 0.55 \\
\hline 7 & 0.48 & 0.49 & 35 & 0.50 & 0.65 \\
\hline 8 & 0.62 & 0.78 & 36 & 0.83 & 0.74 \\
\hline 9 & 0.82 & 0.55 & 37 & 0.70 & 0.53 \\
\hline 10 & 0.70 & 0.53 & 38 & 0.66 & 0.46 \\
\hline 11 & 0.76 & 0.65 & 39 & 0.59 & 0.73 \\
\hline 12 & 0.66 & 0.46 & 40 & 0.48 & 0.49 \\
\hline 13 & 0.59 & 0.73 & 41 & 0.62 & 0.78 \\
\hline 14 & 0.48 & 0.49 & 42 & 0.50 & 0.65 \\
\hline 15 & 0.59 & 0.73 & 43 & 0.71 & 0.87 \\
\hline 16 & 0.48 & 0.49 & 44 & 0.82 & 0.55 \\
\hline 17 & 0.48 & 0.49 & 45 & 0.83 & 0.74 \\
\hline 18 & 0.62 & 0.78 & 46 & 0.66 & 0.46 \\
\hline 19 & 0.83 & 0.74 & 47 & 0.50 & 0.65 \\
\hline 20 & 0.66 & 0.52 & 48 & 0.71 & 0.87 \\
\hline 21 & 0.48 & 0.49 & 49 & 0.82 & 0.55 \\
\hline 22 & 0.70 & 0.53 & 50 & 0.83 & 0.74 \\
\hline 23 & 0.50 & 0.65 & 51 & 0.70 & 0.53 \\
\hline 24 & 0.71 & 0.87 & 52 & 0.66 & 0.46 \\
\hline 25 & 0.82 & 0.55 & 53 & 0.59 & 0.73 \\
\hline 26 & 0.82 & 0.55 & 54 & 0.48 & 0.49 \\
\hline 27 & 0.59 & 0.73 & 55 & 0.62 & 0.78 \\
\hline 28 & 0.73 & 0.59 & & & \\
\hline
\end{tabular}

TABLE 3: The correlation coefficient values between the questionnaire's axes to each other and the tool as a whole.

\begin{tabular}{lcccccc}
\hline Axes & MTM & Reasons & Barriers & Training needs & Training methods & The tool as a whole \\
\hline MTM & 1.0 & $0.87^{* *}$ & $0.69^{* *}$ & $0.72^{*}$ & $0.71^{* *}$ & $0.88^{* *}$ \\
Reasons & & 1.0 & $0.64^{* *}$ & $0.68^{*}$ & $0.68^{* *}$ & $0.86^{* *}$ \\
Barriers & & & 1.0 & $0.76^{*}$ & $0.70^{*}$ & $0.90^{* *}$ \\
Training needs & & & & 1.0 & 1.0 & $0.89^{* *}$ \\
Training methods & & & & & 1.0 \\
The tool as a whole & & & & & \\
\hline
\end{tabular}

${ }^{*}$ Statistical significance at the level of significance $0.05 .{ }^{* *}$ Statistical significance at the level of significance 0.01 .

TABLE 4: The coefficient of internal consistency, Cronbach's alpha, return constancy of the axes, and the total score.

\begin{tabular}{|c|c|c|}
\hline Axes & Repetition constancy (Pearson correlation coefficient) & Internal consistency (Cronbach's alpha) \\
\hline MTM & 0.92 & 0.85 \\
\hline Reasons & 0.86 & 0.88 \\
\hline Barriers & 0.93 & 0.94 \\
\hline Training needs & 0.92 & 0.91 \\
\hline Training methods & 0.91 & 0.93 \\
\hline The tool as a whole & 0.94 & 0.95 \\
\hline
\end{tabular}

To answer the $5^{\text {th }}$ question, the averages and standard deviations of the sample responses were calculated for the questionnaire on the UOH staff's use of MTM, as in Table 9.

Table 9 shows that the general average of responses on the fifth axis was 2.17 , indicating that there is a consensus to a degree (somewhat agree) in the fifth axis. The standard deviation of the general mean of the axis was 0.376 , indicating homogeneity among the responses.

To answer the $6^{\text {th }}$ question, "Are there statistically significant differences at a significance level of 0.05 in the responses to the questionnaire on the use of MTM by the UOH Staff due to a specific variable (gender, academic rank, 
TABLE 5: Means and standard deviations for the questionnaire in the first axis: the degree to which UOH staff use MTM.

\begin{tabular}{|c|c|c|c|c|c|}
\hline Rank & No. & MTM & Mean & Standard deviation & Degree of use \\
\hline 15 & 1 & Problem solving & 2.46 & 0.620 & Use \\
\hline 4 & 2 & KWL teaching cognitive & 1.24 & 0.431 & I do not use \\
\hline 16 & 3 & Mind maps & 2.32 & 0.707 & Use somewhat \\
\hline 10 & 4 & Cognitive load & 1.23 & 0.441 & I do not use \\
\hline 8 & 5 & Brainstorming & 2.18 & 0.703 & Use somewhat \\
\hline 14 & 6 & Inductive learning & 2.24 & 0.734 & Use somewhat \\
\hline 7 & 7 & Inquiry learning & 1.28 & 0.464 & I do not use \\
\hline 5 & 8 & Guided discovery & 2.25 & 0.620 & Use somewhat \\
\hline 3 & 9 & Project-based & 2.31 & 0.616 & Use somewhat \\
\hline 13 & 10 & Reciprocal learning & 2.37 & 0.638 & Use \\
\hline 12 & 11 & Think-pair-share & 1.30 & 0.536 & I do not use \\
\hline 1 & 12 & Peer evaluation & 1.32 & 0.530 & I do not use \\
\hline 11 & 13 & Learning by modeling & 2.62 & 0.568 & Use \\
\hline 9 & 14 & Mastery learning & 1.35 & 0.571 & I do not use \\
\hline 6 & 15 & Roleplaying & 2.20 & 0.792 & Use somewhat \\
\hline 2 & 16 & Peer learning & 2.26 & 0.732 & Use somewhat \\
\hline \multicolumn{3}{|c|}{$\begin{array}{l}\text { The first axis: the degree to which the UOH staff use } \\
\text { MTM }\end{array}$} & 1.94 & 0.184 & Use somewhat \\
\hline
\end{tabular}

The averages for the items of this axis were 1.23-2.62.

TABLE 6: The averages and standard deviations of the paragraphs of the questionnaire in the $2^{\text {nd }}$ axis: the reasons for the use.

\begin{tabular}{|c|c|c|c|c|c|}
\hline Rank & No. & Item & Mean & $\begin{array}{r}\text { Standard } \\
\text { deviation }\end{array}$ & Degree of use \\
\hline 2 & 1 & Its ability to stimulate students' thinking and attention & 2.38 & 0.729 & I agree \\
\hline 10 & 2 & $\begin{array}{l}\text { It emphasizes the interaction between teacher and learner during its } \\
\text { implementation }\end{array}$ & 2.00 & 0.636 & $\begin{array}{l}\text { I somewhat } \\
\text { agree }\end{array}$ \\
\hline 9 & 3 & Its suitability for the scientific content and the nature of the course & 2.09 & 0.750 & $\begin{array}{l}\text { I somewhat } \\
\text { agree }\end{array}$ \\
\hline 4 & 4 & Feel its effectiveness in achieving its goals & 2.31 & 0.679 & $\begin{array}{l}\text { I somewhat } \\
\text { agree }\end{array}$ \\
\hline 5 & 5 & I think it takes into account individual differences & 2.21 & 0.624 & $\begin{array}{l}\text { I somewhat } \\
\text { agree }\end{array}$ \\
\hline 3 & 6 & Suitable for the available financial capabilities & 2.35 & 0.592 & I agree \\
\hline 1 & 7 & Mastery of how to use it & 2.40 & 0.653 & I agree \\
\hline 6 & 8 & It fits the modern teacher's role as a mentor & 2.12 & 0.681 & $\begin{array}{l}\text { I somewhat } \\
\text { agree }\end{array}$ \\
\hline 8 & 9 & I think it saves the professor's time and effort & 2.04 & 0.664 & $\begin{array}{l}\text { I somewhat } \\
\text { agree }\end{array}$ \\
\hline \multirow[t]{2}{*}{7} & 10 & Feel the students enjoy using it in the educational process & 2.11 & 0.758 & $\begin{array}{l}\text { I somewhat } \\
\text { agree }\end{array}$ \\
\hline & & The 2nd axis: the reasons for use & 2.20 & 0.242 & $\begin{array}{l}\text { I somewhat } \\
\text { agree }\end{array}$ \\
\hline
\end{tabular}

TABLE 7: The averages and standard deviations of the paragraphs of the questionnaire in the $3^{\text {rd }}$ axis: obstacles to the staff's use of MTM at the $\mathrm{UOH}$.

\begin{tabular}{lccccc}
\hline Rank & No. & Item & Mean & Standard deviation & Degree of use \\
\hline 5 & 1 & It is weak in terms of stimulating students' thinking and attention & 1.57 & 0.565 & I do not agree \\
8 & 2 & Poor interaction between teacher and learner during implementation & 1.26 & 0.438 & I do not agree \\
4 & 3 & Not suitable for the scientific content & 2.04 & 0.668 & I agree to some extent \\
9 & 4 & I do not feel its effectiveness in achieving its goals & 1.24 & 0.431 & I do not agree \\
10 & 5 & I think it does not take into account individual differences & 1.21 & 0.467 & I do not agree \\
1 & 6 & Its suitability for the financial capabilities available at the university & 2.45 & 0.620 & I agree \\
3 & 7 & I feel I need to practice beforehand & 2.13 & 0.761 I agree to some extent \\
7 & 8 & It does not fit into the modern teacher's role (as a mentor) & 1.28 & 0.451 I do not agree \\
2 & 9 & It consumed the university professor's time and effort & 2.16 & 0.759 & I agree to some extent \\
6 & 10 & I feel distressed among students when using it & 1.37 & 0.485 & I do not agree \\
& The $\mathbf{3}^{\text {rd }}$ axis: obstacles to the use of MTM by the staff at the UOH & 1.55 & 0.225 & I do not agree \\
\hline
\end{tabular}


TABLE 8: Averages and standard deviations of the questionnaire paragraphs in the fourth axis: the training needs of staff at the UOH for MTM.

\begin{tabular}{|c|c|c|c|c|c|}
\hline Rank & No. & MTM & Mean & Standard deviation & Degree of use \\
\hline 10 & 1 & Problem-solving & 1.61 & 0.645 & Weak \\
\hline 1 & 2 & KWL teaching cognitive & 2.46 & 0.620 & High \\
\hline 16 & 3 & Mind maps & 1.12 & 0.328 & Weak \\
\hline 2 & 4 & Cognitive load & 2.45 & 0.620 & High \\
\hline 15 & 5 & Brainstorming & 1.21 & 0.407 & Weak \\
\hline 9 & 6 & Inductive learning & 2.06 & 0.680 & Medium \\
\hline 5 & 7 & Inquiry learning & 2.35 & 0.643 & High \\
\hline 8 & 8 & Guided discovery & 2.16 & 0.767 & Medium \\
\hline 12 & 9 & Project-based & 1.31 & 0.464 & Weak \\
\hline 3 & 10 & Reciprocal learning & 2.38 & 0.704 & High \\
\hline 4 & 11 & Think-pair-share & 2.36 & 0.713 & High \\
\hline 14 & 12 & Peer evaluation & 1.27 & 0.444 & Weak \\
\hline 7 & 13 & Learning by modeling & 2.19 & 0.748 & Medium \\
\hline 11 & 14 & Mastery learning & 1.36 & 0.481 & Weak \\
\hline 13 & 15 & Roleplaying & 1.30 & 0.459 & Weak \\
\hline 6 & 16 & Peer learning & 2.21 & 0.747 & Medium \\
\hline \multicolumn{3}{|c|}{$\begin{array}{l}\text { The fourth axis: the training needs of staff at the UOH for } \\
\text { MTM }\end{array}$} & 1.86 & 0.196 & Medium \\
\hline
\end{tabular}

years of experience, or academic specialization)?," the following was done:

(i) Comparison by gender: a T-test was used to compare responses according to gender, as in Table 10: For the first axis, Table 11 shows that the value of the $t$-test was 0.932 with the level of significance as 0.353 , a nonstatistically significant value at a level of significance of 0.05 among the averages of responses according to gender in the first axis. Regarding the second axis, the value of the $t$-test was 0.369 with a level of significance of 0.712 , which is statistically nonsignificant at a level of 0.05 among the averages of gender-based responses. Regarding the third axis, the value of the $t$-test was 0.104 , with a level of significance of 0.918 , which is statistically nonsignificant at a level of 0.05 among the gender-based averages of responses. Concerning the fourth axis, the value of the $t$-test was 1.498 at a level of significance of 0.063 , which is a nonstatistically significant value at a level of 0.05 among the averages of gender-based responses. Finally, for the fifth axis, the $t$-test was 1.737 , with a level of significance of 0.084 , which is nonstatistically significant at a level of 0.05 among the averages of the gender-based responses.

(ii) Comparison by academic rank: the monoanalysis of the variance F-test was used to compare responses according to the academic rank as shown in Table 10:

Regarding the results of the first axis, the $F$-test value was 2.048 with a statistical significance of 0.109 , statistically nonsignificant at 0.05 . This indicates that there are no statistically significant differences at 0.05 regarding scientific rank.
Regarding the second axis, the $F$-test result was 0.110 with a statistical significance of 0.954 which was statistically nonsignificant at 0.05 . There are statistically nonsignificant differences at 0.05 in the second axis according to the scientific rank. Regarding the third axis, the F-test result was 0.187 with a statistical significance of 0.905 , which is statistically nonsignificant at 0.05 . There are no statistically significant differences at 0.05 according to academic rank. Concerning the fourth axis, the $F$-test result was 0.761 with a statistical significance of 0.518 , statistically nonsignificant at 0.05 . There are no statistically significant differences at 0.05 in the fourth axis per scientific rank. Finally, the fifth axis $F$-test result was 0.841 with a statistical significance of 0.473 . It is statistically nonsignificant at 0.05 . There are no statistically significant differences at 0.05 in the fifth axis per scientific rank. This agrees with the findings of Barhoum, [35]; Al-Balawi [20]; AlKhalifah and Farhan [21]; and Nassar [34].

(iii) Comparison according to years of experience: the monoanalysis of the variance $F$-test was used to compare the sample responses according to the years of experience as in Table 12.

For the first axis, the $F$-test result was 0.267 with a statistical significance of 0.766 , statistically nonsignificant at 0.05 . There are no statistically significant differences at 0.05 in the first axis according to years of experience. Regarding the second axis, the $F$-test result was 0.327 with a statistical significance of 0.722 . It is statistically nonsignificant at 0.05 . There are no statistically significant differences at 0.05 in the second axis according to years of experience. 
TABLE 9: The averages and standard deviations of the questionnaire, in the fifth axis: the proposed training methods to develop the skills of staff at the UOH in the use of MTM.

\begin{tabular}{|c|c|c|c|c|c|}
\hline Rank & No. & The format of the proposed training & Mean & Standard deviation & Degree of approval \\
\hline 3 & 3 & Theoretical-practical & 1.70 & 0.628 & I somewhat agree \\
\hline 2 & 2 & My application is practical & 2.29 & 0.681 & I somewhat agree \\
\hline 1 & 1 & Electronic & 2.51 & 0.722 & I agree \\
\hline \multicolumn{3}{|c|}{$\begin{array}{l}\text { The fifth axis: the proposed training methods to develop the } \\
\text { skills of the UOH staff on the use of MTM }\end{array}$} & 2.17 & 0.376 & I somewhat agree \\
\hline
\end{tabular}

TABLE 10: Results of the F-test for a comparison between the averages of responses to the questionnaire on the reality of the use of MTM by staff at the $\mathrm{UOH}$ according to academic rank.

\begin{tabular}{|c|c|c|c|c|c|c|}
\hline Axis & Sources of variance & Sum of squares & Degrees of freedom & Average of squares & $F$-test & Statistical significance \\
\hline \multirow{3}{*}{ First } & Between groups & .0 .204 & 3 & 0.068 & \multirow{3}{*}{2.048} & \multirow{3}{*}{0.109} \\
\hline & Within groups & 5.300 & 160 & 0.033 & & \\
\hline & Total & 5.504 & 163 & & & \\
\hline \multirow{3}{*}{ Second } & Between groups & 0.020 & 3 & 0.007 & \multirow{3}{*}{0.110} & \multirow{3}{*}{0.954} \\
\hline & Within groups & 9.559 & 160 & 0.060 & & \\
\hline & Total & 9.579 & 163 & & & \\
\hline \multirow{3}{*}{ Third } & Between groups & 0.029 & 3 & .0 .010 & \multirow{3}{*}{0.187} & \multirow{3}{*}{0.905} \\
\hline & Within groups & 8.198 & 160 & 0.054 & & \\
\hline & Total & 8.227 & 163 & & & \\
\hline \multirow{3}{*}{ Fourth } & Between groups & 0.088 & 3 & 0.029 & \multirow{3}{*}{0.761} & \multirow{3}{*}{0.518} \\
\hline & Within groups & 6.165 & 160 & 0.039 & & \\
\hline & Total & 6.253 & 163 & & & \\
\hline \multirow{3}{*}{ Fifth } & Between groups & 0.357 & 3 & 0.119 & \multirow{3}{*}{0.841} & \multirow{3}{*}{0.473} \\
\hline & Within groups & 22.643 & 163 & 0.142 & & \\
\hline & Total & 23.000 & 163 & & & \\
\hline
\end{tabular}

Regarding the third axis, the $F$-test result was 0.108 with a statistical significance of 0.898 , statistically nonsignificant at 0.05 . There are no statistically significant differences at 0.05 in the third axis according to years of experience. Concerning the fourth axis, the $F$-test result was 0.445 with a statistical significance of 0.641 , statistically nonsignificant at 0.05 . There are no statistically significant differences at 0.05 in the fourth axis according to years of experience. Finally, for the fifth axis, the $F$ test result was 1.413 with a statistical significance of 0.247 , statistically nonsignificant at 0.05 . There are no statistically significant differences at 0.05 in the fifth axis according to years of experience.

Years of experience did not affect MTM teaching strategies or training needs. This can be attributed to the university's keenness to continuously improve the expertise of faculty members by enrolling them in training courses on MTM. Also, it may be attributed to promotion prerequisites. These results agree with Sakkar [27]; Al Asmari [15]; Al-Khalifa and Farhan [21]; Nassar [34].

(iv) Comparison according to academic specialization: The monoanalysis of the variance $F$-test was used to compare responses according to academic specialization as in Table 13.

In the first axis, the $F$-test result was 1.981 with a statistical significance of 0.141 , statistically nonsignificant at 0.05 . There are no statistically significant differences at 0.05 in the first axis according to the academic specialization. For the second axis, the $F$-test result was 0.278 with a statistical significance of 0.758 , statistically nonsignificant at 0.05 . There are no statistically significant differences at 0.05 in the second axis according to the academic specialization. Regarding the third axis, the $F$-test result was 0.012 with a statistical significance of 0.988 , statistically nonsignificant at 0.05 . There are no statistically significant differences at 0.05 in the responses to the third axis according to the academic specialization. Regarding the fourth axis, the $F$-test result was 2.107 with a statistical significance of 0.125 , statistically nonsignificant at 0.05 . There are no statistically significant differences at 0.05 in the fourth axis according to the academic specialization. Finally, the fifth $F$-test result was 0.258 with a statistical significance of 0.773 , statistically nonsignificant at 0.05 . There are no statistically significant differences at 0.05 in the fifth axis according to the academic specialization.

\section{Discussion}

The results showed that the most important reason for using MTM during the COVID-19 pandemic was "Mastery of how to use it." This is attributed to the staff's love for their profession and MTM and their adaptability to the pandemic. These results 
TABLE 11: Results of a $t$-test for a comparison between the averages of responses to the questionnaire on the reality of the use of MTM by the staff at the $\mathrm{UOH}$ by gender.

\begin{tabular}{|c|c|c|c|c|c|c|}
\hline The axis & Gender & No. & Mean & Standard deviation & $t$-value & Statistical significance \\
\hline \multirow{2}{*}{ First } & Male & 104 & 1.95 & 0.191 & \multirow{2}{*}{0.932} & \multirow{2}{*}{0.353} \\
\hline & Female & 60 & 1.92 & 0.171 & & \\
\hline \multirow{2}{*}{ Second } & Male & 104 & 2.20 & 0.242 & \multirow{2}{*}{0.369} & \multirow{2}{*}{0.712} \\
\hline & Female & 60 & 2.21 & 0.244 & & \\
\hline \multirow{2}{*}{ Third } & Male & 104 & 1.55 & 0.245 & \multirow{2}{*}{0.140} & \multirow{2}{*}{0.918} \\
\hline & Female & 60 & 1.56 & 0.186 & & \\
\hline \multirow{2}{*}{ Fourth } & Male & 104 & 1.86 & 0.180 & \multirow{2}{*}{1.498} & \multirow{2}{*}{0.063} \\
\hline & Female & 60 & 1.91 & 0.214 & & \\
\hline \multirow{2}{*}{ Fifth } & Male & 104 & 2.13 & 0.389 & \multirow{2}{*}{1.737} & \multirow{2}{*}{0.084} \\
\hline & Female & 60 & 2.23 & 0.343 & & \\
\hline
\end{tabular}

TABLE 12: Results of the F-test for a comparison of the averages of responses to the questionnaire on the reality of the use of modern teaching methods by the staff at the UOH according to the years of experience variable.

\begin{tabular}{|c|c|c|c|c|c|c|}
\hline Axis & Sources of variance & Sum of squares & Degrees of freedom & Average of squares & $F$-test & Statistical significance \\
\hline \multirow{3}{*}{ First } & Between groups & 0.018 & 2 & 0.099 & & \\
\hline & Within groups & 5.485 & 161 & 0.034 & 0.267 & 0.766 \\
\hline & Total & 5.504 & 163 & & & \\
\hline \multirow{3}{*}{ Second } & Between groups & 0.039 & 2 & 0.019 & & \\
\hline & Within groups & 9.540 & 161 & 0.059 & 0.327 & 0.722 \\
\hline & Total & 9.579 & 163 & & & \\
\hline \multirow{3}{*}{ Third } & Between groups & 0.011 & 2 & 0.005 & & \\
\hline & Within groups & 8.216 & 161 & 0.051 & 0.108 & 0.898 \\
\hline & Total & 8.227 & 163 & & & \\
\hline \multirow{3}{*}{ Fourth } & Between groups & 0.034 & 2 & 0.017 & & \\
\hline & Within groups & 6.218 & 161 & 0.039 & 0.445 & 0.641 \\
\hline & Total & 6.253 & 163 & & & \\
\hline \multirow{3}{*}{ Fifth } & Between groups & 0.397 & 2 & 0.198 & & \\
\hline & Within groups & 22.603 & 161 & 0.140 & 1.413 & 0.247 \\
\hline & Total & 23.000 & 163 & & & \\
\hline
\end{tabular}

TABle 13: Results of the F-test for a comparison between the averages of responses to the questionnaire on the use of MTM by faculty members at the $\mathrm{UOH}$ according to the variable of the academic specialization.

\begin{tabular}{|c|c|c|c|c|c|c|}
\hline Axis & Sources of variance & Sum of squares & Degrees of freedom & Average of squares & $F$-test & Statistical significance \\
\hline \multirow{3}{*}{ First } & Between groups & 0.132 & 2 & 0.066 & & \\
\hline & Within groups & 5.371 & 161 & 0.033 & 1.981 & 0.141 \\
\hline & Total & 5.504 & 163 & & & \\
\hline \multirow{3}{*}{ Second } & Between groups & 0.033 & 2 & 0.016 & & \\
\hline & Within groups & 9.546 & 161 & 0.059 & 0.278 & 0.758 \\
\hline & Total & 9.579 & 163 & & & \\
\hline \multirow{3}{*}{ Third } & Between groups & 0.001 & 2 & 0.001 & & \\
\hline & Within groups & 8.226 & 161 & 0.051 & 0.012 & 0.988 \\
\hline & Total & 8.227 & 163 & & & \\
\hline \multirow{3}{*}{ Fourth } & Between groups & 0159 & 2 & 0.080 & & \\
\hline & Within groups & 6.093 & 161 & 0.038 & 2.107 & 0.125 \\
\hline & Total & 6.253 & 163 & & & \\
\hline \multirow{3}{*}{ Fifth } & Between groups & .0 .073 & 2 & 0.037 & & \\
\hline & Within groups & 22.927 & 161 & 0.142 & 0.773 & 0.258 \\
\hline & Total & 23.000 & 163 & & & \\
\hline
\end{tabular}

could be linked to other personal variables and aptitudes, confirmed by the phrase "its ability to stimulate the thinking and attention of students," which came in second place in the list of reasons for use. This indicates the faculty's awareness on the importance of the paradigm shift from the teacher as a provider of knowledge to the student as an acquirer of 
knowledge. It is necessary to use methods that incentivize learning. This agrees with the findings of Ito and Kawazoe [25], Dann, [32] and Awad [6] but disagrees with those of Al-Khalifa and Farhan [21] and Al-Ami and Laftah [36], revealing that faculty members spend lecture time transmitting information, besides the apparent faculty members' lack of knowledge of modern teaching methods.

The results also indicate a preference for instructional methods, where students interact within activities until they achieve educational goals. The results show that the modeling learning method came up with the highest average, explainable by the fact that the modeling learning method is characterized by providing information and forming a mental perception of the relationships between objects, phenomena, or events using facilitated simulations with explanation, interpretation, and prediction through two important means: sound and image. These media allow students to receive information in more than one sense and to fix the information. Faculty members preferred this strategy as it helps students learn according to their abilities and understanding, prompting them to interact. Problem solving came in second place, confirming the preference of assigning students active roles according to the available possibilities in recognition of the importance of diversifying teaching strategies through holding workshops, courses, and training programs related to how to employ teaching strategies and methods at the undergraduate level.

This agrees with the findings of Al-Khalifah and Farhan [21] and Mahasneh et al. [18], who confirmed the high degree of staff familiarity with modern teaching strategies and methods. However, it disagrees with the results of AlBalwi [20] and Alhirtani [1], whose results revealed that peer-teaching strategies and peer evaluation came in last among modern teaching strategies, while lectures were the most common method due to lecturers' inability to apply some modern teaching methods.

These results are attributed to the staff's awareness of the importance of modern teaching methods and their ability to overcome learning problems during the COVID-19 pandemic, and that is what the University of Hail offers in the field of professional growth, enhancing their self-confidence and providing necessary information, trends, and skills. Therefore, their training needs came in the middle degree, confirmed by the results of the previous axis that MTM are used at a degree "to some extent" from their point of view, and the results are consistent with those of Rababa'a [19], AlBalawi [20], and Abu Al-Fadl (2014) that indicated the need to be trained in the use of teaching methods related to developing scientific thinking skills and the KWL method. The aforementioned study agreed that the need for staff training was moderate. These results differ from the findings of Abdelali (2012) and Rababa'a [19], who believed that the staff's need to train was high.

The results indicate no statistically significant differences attributed to gender, academic rank, years of experience, or academic specialization, agreeing with the findings of $\mathrm{Al}$ Balawi [20], Khalifah and Farhan [21], and Mahasna et al. [18] while differing with those of Sakr's study [27], which found differences in favor of males. This may be attributable to the fact that the UOH faculty staff, regardless of their specializations (engineering/health/humanitarian), are aware of the importance of training needs as per their professional roles during the COVID-19 pandemic. Their responses did not vary according to the variation in specialization. The results of the study disagree with those of Al-Asmari [15], Al-Khalifah and Farhan [21], Barhoum, [35] and Al-Shehri [14], illustrating differences in the responses of faculty members to their training needs as per academic specialization.

\section{Conclusion}

The study aimed to evaluate the UOH staff's use of MTM during the COVID-19 pandemic, identify the most important causes of use, obstacles, and foremost training needs and their implementation, and reveal significant individual differences in the extent of MTM usage-attributed to gender, academic rank, experience, or academic specialization.

The study found that the staff use MTM due to their awareness on their importance and observance of many educational principles that contribute to preparing and refining the balanced and integrated personality of the learner. Moreover, the results indicated the importance of electronic and applied training on MTM usage to improve university education outcomes. It is necessary to know everything related to these active learning and continuous education focused methods due to their direct impact on the educational process in terms of enhancing confidence and learning motivation of students. Academic rank, years of experience, and academic specialization did not influence training needs.

The results also highlighted the importance of sufficient preparation of faculty members to use MTM effectively (through training on mind maps, cognitive burden, inductive learning, directed discovery, and project-based teaching), upgrading university buildings to form an ideal classroom/laboratory MTM-friendly environment, and working to motivate them to use active learning strategies, provided that the training needs be among the principles of evaluating faculty members. It is recommended to study teaching strategies' effectiveness from the University of Hail student's viewpoint during the COVID-19 outbreak to investigate activities to develop some effective teaching methods among university faculty members. Also, it is important to research the relationship between the teaching practices of staff and the development of some variables (such as thinking/self-organization) among students.

\section{Data Availability}

The data will be made available upon request to the author.

\section{Conflicts of Interest}

The author declares no conflicts of interest.

\section{References}

[1] N. Alhirtani, "The use of modern teaching methods in teaching Arabic language at higher education phase from the point view of Arabic language professors-a case of a premier 
university," International Education Studies, vol. 13, no. 1, pp. 32-41, 2020.

[2] E. M. A. Musa, "Obstacles to using some modern teaching methods from the viewpoint of secondary school teachers in Marj City," Journal of University of Benghazi, College of Education in Al-Marj, vol. 46, no. 46, pp. 1-19, 2020.

[3] D. Llewellyn, Teaching High School Science through Inquiry: A Case Study Approach, NSTA Press \& Corwin Press, Thousand Oaks, CA, USA, 2005.

[4] R. Akbari, F. Behzadpoor, and B. Dadvand, "Development of English language teaching reflection inventory," System, vol. 38, no. 2, pp. 211-227, 2010.

[5] E. D. Theresa, "Different teaching methods: a panacea for effective curriculum implementation in the classroom," International Journal of Secondary Education. Special Issue: Teaching Methods and Learning Styles in Education, vol. 3, no. 6, pp. 77-87, 2015.

[6] A. S. M. Awad, "The effect of using a project-based teaching strategy on developing environmental trends among students of the faculty of educational sciences and arts of the UNRWA," International Journal of Educational Research, UAE University, vol. 2, no. 41, 2017.

[7] I. Al-Amoush and A. Al-Juhani, "The effect of using the reciprocal teaching method on developing reading comprehension skills among third-grade intermediate students in Qurayyat Governorate, Kingdom of Saudi Arabia," Taibah University Journal for Educational Sciences, vol. 11, no. 1, pp. 1-14, 2015.

[8] A. Rouhollahi, "Effective teaching methods in higher education: requirements and barriers," Journal of Advances in Medical Education \& Professionalism, vol. 4, no. 4, pp. 169179, 2016.

[9] M. Martin, G. Laciste, and K. Concepcion, "Prevalence of modern teaching method among senior high school students," EDUCATUM Journal of Science, Mathematics and Technology, vol. 6, no. 1, 2019.

[10] A. A. Al-Dariwesh, "The degree to which stafat King Saud University use e-learning from the viewpoint of graduate students and graduates," Journal of the Association of Arab Universities, vol. 40, no. 2, pp. 53-70, 2020.

[11] A. T. O. Ali, "The reality of using smart classroom technologies among stafin the college of education at King Saud University," Shaqra University Journal, vol. 8, pp. 63-85, 2017.

[12] A. Al-Saeed, A Descriptive Study of the Use of Smart Classrooms by Stafat King Saud University, King Saud University, Riyadh, Saudi Arabia, 2013.

[13] A. M. Shoaib and I. H. Asfour, A System for Training Stafbetween Reality and Expectations, The first Arab Forum for the Faculty Development Center at Benha University, Banha, Egypt, 2017.

[14] M. H. A. Al-Shehri, "A proposed scenario for employing modern teaching methods in light of the necessary needs of Stafin the college of science and arts in Sharurah governorate," Professor Forum Magazine, vol. 17, no. 17, pp. 50-80, 2016.

[15] M. A. Al-Asmari, "The training needs of staff at the University of Tabuk in light of the requirements for the quality of university education," International Journal of Educational and Psychological Studies, vol. 7, no. 3, pp. 454-472, 2020.

[16] Y. Abouelenein, "Training needs for faculty members: towards achieving quality of University Education in the light of technological innovations," Educational Research and Reviews, vol. 11, 2016.

[17] M. Mangut and O. Uche, "Effects of hybrid active learning strategy on students' understanding of direct current electricity concepts in Nigerian secondary schools," International Journal of Learning, Teaching and Educational Research, vol. 13, no. 2, pp. 77-87, 2015.

[18] O. Mahasneh, H. Al-Tura, and T. Al-Messaideen, "The extent of the familiarity and employment of Stafat Shobak and Ma'an University Colleges with the strategies and methods of teaching during their teaching of university courses," Journal of the College of Education, Ain Shams University, vol. 37, no. 2, 2013.

[19] O. A. Rababa'a, “Training needs of Stafin official Jordanian universities in light of the requirements of a knowledge economy," International Journal of Educational Research, United Arab Emirates University, vol. 41, no. 3, pp. 73-101, 2017.

[20] A. M. Al-Balawi, "The effect of teaching using the (K.W.L) strategy on the achievement of students of theoretical disciplines at the college of science and arts in Al-Ula in the subject of statistical applications in the humanities," International Journal of Special Education, vol. 5, no. 5, pp. 240-255, 2016.

[21] R. S. Al-Khalifah and T. M. Farhan, "Obstacles to using modern teaching strategies among Stafin Islamic studies departments in Saudi universities from their point of view," The Educational Journal, Kuwait University-Scientific Publishing Council, vol. 32, no. 128, pp. 279-314, 2018.

[22] L. Tabata and L. Johnsrud, "The impact of faculty attitudes toward technology, distance education, and innovation," Research in Higher Education, vol. 49, pp. 625-646, 2008.

[23] R. J. Beichner, "History and evolution of active learning spaces," New Directions for Teaching and Learning, vol. 2014, no. 137, 16 pages, 2014.

[24] S. Hartikainen, H. Rintala, L. Pylväs, and P. Nokelainen, “The concept of active learning and the measurement of learning outcomes: a review of research in engineering higher education," Education Sciences, vol. 9, no. 4, 2019.

[25] H. Ito and N. Kawazoe, "Active learning for creating innovators: employability skills beyond industrial needs," International Journal of Higher Education, vol. 4, pp. 81-91, 2015.

[26] C. Konopka, M. Adaime, and P. Mosele, "Active teaching and learning methodologies: some considerations," Creative Education, vol. 6, 2015.

[27] A. N. Sakr, "The degree to which members of the teaching staff of the Arabic language for non-native speakers use the teaching methods at the University of Jordan from their point of view," Jordan Educational Society, the Jordanian Educational Journal, vol. 2, no. 1, pp. 268-295, 2017.

[28] Y. D. Kristanto, “Technology-enhanced pre-instructional peer assessment: exploring students' perceptions in a statistical methods course," Research and Evaluation in Education, vol. 4, no. 2, pp. 105-116, 2018.

[29] V. Hoogerheide, S. M. M. Loyens, and T. Van Gog, "Learning from video modeling examples: does gender matter?" Instructional Science, vol. 44, no. 1, pp. 69-86, 2015.

[30] E. Pizzini, "A rational for and the development of a collaborative problem-solving model of instruction in science education," Science Education, vol. 73, no. 5, pp. 523-534, 2015.

[31] C. E. Rizi, M. Najafipour, F. Haghani, and S. Dehghan, "The effect of the using the brainstorming method on the academic achievement of students in grade five in tehran elementary schools," Procedia-Social and Behavioral Sciences, vol. 83, pp. 230-233, 2013.

[32] C. Dann, "Is project based learning more effective than direct instruction in school science classroom," Masters thesis, University of Manitoba, Winnipeg, Canada, 2012. 
[33] A. A. Mohamad and M. H. Al-Faqih, "Evaluating the training needs of Stafat Najran University in light of the requirements of the national commission for academic accreditation and assessment standards," Journal of the Faculty of Education, Assiut University, vol. 31, no. 4, 2015.

[34] N. M. Nassar, "Training needs of Stafat the arab open university in the Kingdom of Saudi Arabia (case study)," Journal of the Association of Arab Universities, vol. 39, no. 2, pp. 93-118, 2019.

[35] A. H. Barhoum, "Training needs of faculty members in Palestinian universities, the Islamic University, a case study," Journal of Psychological and Educational Sciences, vol. 25, no. $4,2017$.

[36] S. Al-Ami and A. Z. Laftah, "The extent to which effective teaching is achieved (teaching practices) for a university professor," Arabian Gulf Journal, UAE, vol. 3-4, no. 41, 2013. 